\title{
SOBRE O LATANOPROST E A PRESSÃO INTRAOCULAR EM CÃES.
}

ANTÔNIO FELIPE P.F. WOUK ${ }^{1}$; MARIA FERNANDA TORRES ${ }^{2}$; ELIZABETH LEMOS LEAL ${ }^{2}$

${ }^{1}$ Departamento de Medicina Veterinária. ${ }^{2}$ Curso de Graduação em Ciências Veterinárias, Setro de Ciências Agrárias, Universidade Fedral do Paraná.

O grupo farmacológico das Prostaglandinas com o qual se embricam os da Prostaciclina, do Tromboxano A2 e dos Leucotrienos é, atualmente, foco de grande interesse em Biologia. Sabe-se há alguns anos que as Prostaglandinas aplicadas topicamente, em doses baixas, reduzem a Pressão Intraocular (PIO) em cães, gatos, macacos e no homem (BITO, 1989). Nos glaucomas a luta para baixar a PIO é mandatória e neste sentido o arsenal terapêutico se expande continuamente. Recentemente sintetizou-se uma prostaglandina, o Latanoprost, que é comercializado a uma concentração de $0,005 \%$ com o nome de Xalatan como antiglaucomatoso de uso tópico sob a forma de colírio. A droga age aumentando o fluxo uveo-escleral do humor aquoso. Seis cães com PIO normal receberam em um dos olhos uma dose única diária de Xalatan às $20 \mathrm{~h}$ enquanto o olho adelfo recebeu um placebo. Os animais foram mantidos hospitalizados por 6 dias e o teste foi conduzido de forma cega. A PIO foi medida por tonometria de aplanação (Tonopen) a partir da $8 \mathrm{~h}$ do segundo dia. Foram realizadas quatro medições diárias sendo uma delas à noite. Veificouse uma redução noturna e diurna uniformes da ordem de $22 \%$ na PIO dos olhos tratados. Estes resultados sugerem a realização de um estudo clínico com o Latanoprost no glaucoma de cães. 